\title{
Factors associated with dairy farmers' satisfaction and preparedness to adopt recommendations after veterinary herd health visits
}

\author{
Caroline Ritter, ${ }^{1 *}$ Cindy L. Adams, ${ }^{2}$ David F. Kelton, ${ }^{3}$ and Herman W. Barkema ${ }^{1}$ \\ ${ }^{1}$ Department of Production Animal Health, Faculty of Veterinary Medicine, University of Calgary, 2500 University Drive, Calgary, AB, T2N 1N4, \\ Canada \\ ${ }^{2}$ Department of Veterinary Clinical and Diagnostic Sciences, Faculty of Veterinary Medicine, University of Calgary, 2500 University Dr., Calgary, \\ $\mathrm{AB}, \mathrm{T} 2 \mathrm{~N} 1 \mathrm{~N} 4$, Canada \\ ${ }^{3}$ Department of Population Medicine, University of Guelph, 50 Stone Rd., Guelph, ON, N1G 2W1, Canada
}

\section{ABSTRACT}

Herd health and production consultancy are important aspects of the modern dairy veterinary practice; therefore, veterinary farm visits will likely be more successful if veterinary practitioners communicate effectively and meet farmers' expectations. Objectives were to assess dairy farmers' satisfaction with veterinary advisors and their perceived preparedness to adopt veterinary advice. Furthermore, we assessed whether farmers' satisfaction and preparedness to adopt advice were associated with specific predictor variables; that is, general (demographic) factors of veterinarians or farmers, communication tools used by veterinarians, and veterinarians' affective attributes during the farm visit. Audio-video recordings of 14 dairy veterinarians during 70 herd health and production management farm visits were analyzed using the Roter interaction analysis system. Demographic data, farmers' satisfaction, and farmers' preparedness to adopt advice were obtained by using questionnaires. Overall, farmers were satisfied with their veterinarian's communication during farm visits and $58 \%$ of farmers felt "absolutely" prepared to follow veterinary recommendations. Based on multivariable regression analysis, farmers' satisfaction was positively associated with their level of education and the amount of talk the veterinarian dedicated to counseling the farmer. However, satisfaction was negatively association with the ratio between veterinarian talk and farmer talk. In addition to various demographic variables, farmers' preparedness to adopt veterinary advice was positively associated with their satisfaction. Other predictor variables for farmers' preparedness to follow recommendations included increased veterinary counseling and frequent herd data discussions, whereas there was a negative relationship between number of

Received October 10, 2018.

Accepted January 2, 2019.

*Corresponding author: cmnritte@ucalgary.ca farmer questions and dominance of the veterinarian during the farm visit. Identification of factors influencing farmers' satisfaction and preparedness to adopt advice will make veterinary communication more effective and could inform training of veterinarians in communication.

Key words: veterinary advice, dairy farm consultancy, dairy farmer adherence, farm management

\section{INTRODUCTION}

Effective communication is an important clinical skill for medical professionals when interacting with patients (human medicine; e.g., Sari et al., 2016) or clients (veterinary medicine; e.g., Coe et al., 2008). Whereas studies conducted in the veterinary context are still scarce, there is a wealth of knowledge regarding influence of clinical communication on the patient-physician relationship and outcomes of medical encounters. Specifically, there is evidence that communication skills are linked to patient and physician satisfaction, patient adherence, and health outcomes (reviewed by Silverman et al., 2013).

Although veterinary medicine is inherently different from the human medicine context, with the animal owner being the caretaker instead of the patient, general principles that lead to a successful consultation are likely comparable (Williams and Jewell, 2012). For example, physicians' attention to and respect for their patients' or clients' experiences and opinions, as well as shared power and decision-making, have been advocated to improve consultancy quality in human and veterinary medicine (Silverman et al., 2013; Adams and Kurtz, 2017). During the last decades, this concept of "patient-centered care" (human medicine) or "relationship-centered care" (veterinary medicine) has emerged as a key notion describing effective clinical communication and has been demonstrated to increase the success of medical encounters (Kanji et al., 2012; King and Hoppe, 2013). 
Specific communication tools, including empathy statements or open-ended questions, that contribute to patient- or client-centeredness have been directly linked to satisfaction in various medical contexts (Robinson and Heritage, 2006; McArthur and Fitzgerald, 2013). Research in a dairy environment demonstrated that use of these tools was often sparse, which could negatively affect veterinarian-farmer relationships and quality of veterinary consultancy (Jansen et al., 2010). Furthermore, dairy veterinarians were often unaware of farmers' main goals (Derks et al., 2013) and farmer adherence to veterinary advice was poor (Sorge et al., 2010). These examples demonstrated that dairy practitioners' consultancy skills are in need of improvement. However, to our knowledge, associations between dairy veterinarians' specific communication patterns and desired outcomes have not been reported.

In this study, we used on-farm audio-video recordings and questionnaires to assess (1) dairy farmers' satisfaction and their preparedness to adopt veterinary advice after herd health and production management (HH\&PM) farm visits; (2) associations of general factors (e.g., demographics of veterinarians and farmers), communication patterns, and veterinarians' affective attributes with dairy farmers' satisfaction and their preparedness to adopt veterinary recommendations; and (3) whether HH\&PM visit satisfaction was associated with farmers' preparedness to adopt veterinary recommendations.

\section{MATERIALS AND METHODS}

\section{Recruitment of Veterinarians and Dairy Farmers}

Veterinarians with $\geq 10$ dairy clients who practiced within a feasible driving distance $(<750 \mathrm{~km})$ from Calgary, Alberta, Canada, were contacted by email and telephone and asked to participate in the study (Ritter et al., 2018a). Eleven (69\%) of the 16 contacted veterinarians agreed to participate, whereas 5 declined due to lack of time or a lack of comfort with recording farm visits. Thirty dairy practitioners who were enrolled in the Dairy Health Management Continuing Education Program (Ontario Veterinary College, University of Guelph, ON, Canada) were also invited to participate through a group email. Six of the contacted veterinarians (5 from Ontario and 1 from Alberta) agreed to participate. Veterinarians were informed that the objective of this research was to assess veterinarian-farmer communication and that they would receive Can $\$ 100$ if they submitted HH\&PM farm recordings from 7 selfselected farms. Veterinarians were encouraged to enroll a representative sample of their dairy farms in terms of herd size, farm management, and their relationship to the farmer.

Ethics approval was obtained from the University of Calgary's Research Ethics board (protocol REB151800) and veterinarians obtained prior consent from clients to record video and audio.

\section{Collection of Communication Information}

Assessment of veterinarian-farmer communication patterns has been described previously (Ritter et al., 2018a,b). In brief, participating veterinarians were provided with a GoPro camera (Hero3 black edition; GoPro Inc., San Mateo, CA) including a BacPac battery (GoPro Inc.) and an adjustable mount that allowed them to wear the camera on either their head or chest during regular scheduled HH\&PM farm visits. Additionally, veterinarians provided participating farmers with a voice recorder (Portable Digital Voice Recorder 8 GB USB Flash Drive, Etekcity, Anaheim, CA) to ensure sufficient audio quality. Because of ceasing recording due to time constraints (2 veterinarians) or an insufficient number of participating dairy clients (2 veterinarians), only 99 recordings were submitted. Of these, 70 recordings by 14 veterinarians (3-7 recordings per veterinarian) were analyzed. Reasons to exclude recordings from analysis included missing paperwork (i.e., missing questionnaires or consent forms; $\mathrm{n}=7$ ), poor audio quality or insufficient completeness of the recording $(\mathrm{n}=18)$, and subsequent withdrawal of consent by the farmer $(n=2)$. Only when $\geq 3$ recordings of a particular veterinarian were considered for analysis using these exclusion criteria, we analyzed all of their eligible recordings. Therefore, 12 recordings from 3 veterinarians were not included in the study, although each had provided up to 2 suitable recordings. This criterion was applied to reduce the risk of obtaining nonrepresentative data (in previous analyses, veterinary communications were highly variable among HH\&PM farm visits; Ritter et al., 2018b).

\section{Analysis of Recordings and Editing of Communication Codes}

The Roter interaction analysis system (RIAS), a method especially developed for coding medical dialog, was used to analyze veterinary communication patterns (Roter and Larson, 2002). While watching each video, a professional RIAS coder from Johns Hopkins Bloomberg School of Public Health (Baltimore, MD) assigned 1 of 49 mutually exclusive and exhaustive codes to every expression or statement that constituted a complete thought (i.e., communication unit; for examples, 
see Table 1). A quantitative data set was obtained by adding the frequency of coded communication units. For this study, individual communication units, as well as summary measures, were considered for assessment of their association with farmers' satisfaction and preparedness to adopt veterinary advice (Table 1). Selection of these specific communication patterns was based on the Calgary-Cambridge Guide (i.e., a framework for medical interviewing; Petrovski and McArthur, 2015) and evidence from the literature regarding influence on patient or client satisfaction (Silverman et al., 2013; Adams and Kurtz, 2017). Therefore, several veterinarians' communication characteristics were considered predictor variables (Table 1). As a percentage of all veterinarians' talk, communication units allocated to information gathering, education and counseling, and facilitating a positive relationship were calculated (Shaw et al., 2004). The ratio of veterinarians' open- versus closed-ended questions was also considered a predictor (McArthur and Fitzgerald, 2013). Additionally, the ratio of veterinarians' communication units (either information gathering or education/counseling) related to general animal care and understanding the farm as a whole versus communication units related to biomedical topics was obtained (Adams and Kurtz, 2017). The number of veterinarians' empathy statements was considered a separate predictor variable (McArthur and Fitzgerald, 2013). The relationship-centered care score (Shaw et al., 2006) was calculated by dividing communication units that contributed to farmer empowerment, shared decision-making, and veterinarians' interest in the farming enterprise as a whole (e.g., veterinarians' statements of empathy, reassurance, and partnership; questions about animal care topics; and farmer questions) by RIAS codes that indicated a focus on biomedical topics and veterinary dominance (e.g., questions related to biomedical topics, education by the veterinarian, and providing information by the farmer). Hence, a high relationship-centered care score indicated a high relationship-centeredness of the HH\&PM farm visit. In addition to these veterinary-specific communication patterns, a "total talk ratio" was calculated, dividing the total number of communication units spoken by the veterinarian by all communication units spoken by the farmer. Finally, the number of questions expressed by the farmer was also evaluated as a predictor.

The RIAS coder assigned global ratings to each of the recordings on 6-point Likert scales (1 and 6 representing the lowest and highest possible scores, respectively), representing veterinarians' affective characteristics such as warmth, respectfulness, and dominance during the interaction. Global affect ratings were based on communication content, as well as veterinarians'
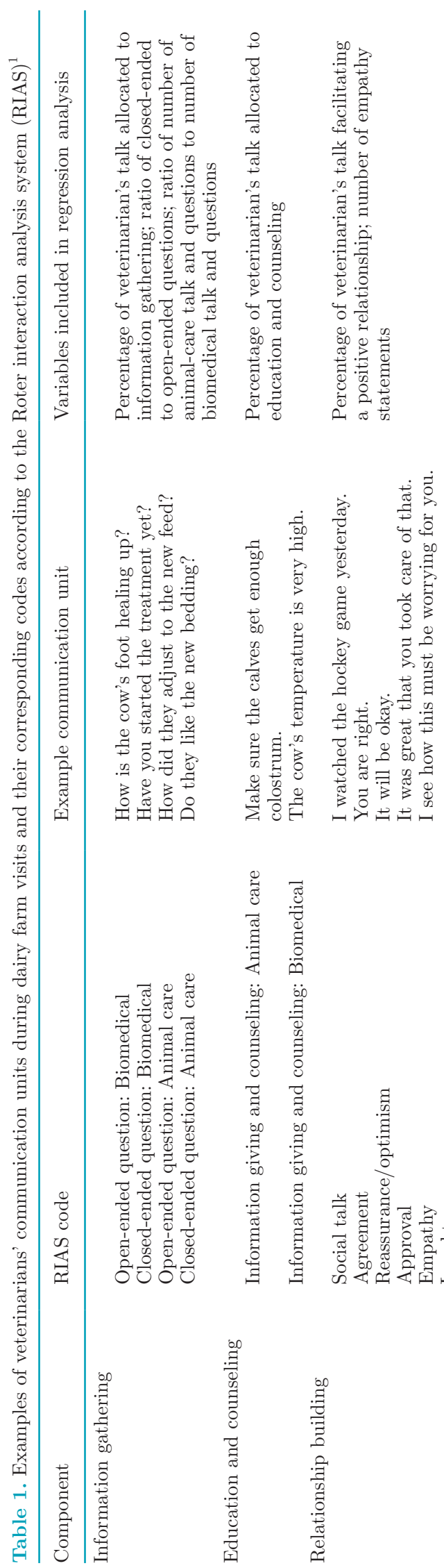

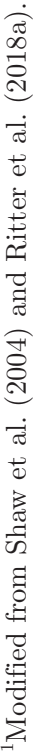


tone of voice and body language (i.e., nonverbal communication). Then, RIAS communication codes with a mean frequency $\geq 1$ across all interactions and global affect ratings were evaluated by assessing intra-rater reliability by recoding 7 interactions at the end of the study.

Three variables not immediately derived from RIAS coding were considered potential effect modifiers, or confounders, of the relationship of veterinary communication patterns with farmers' satisfaction or preparedness to adhere: Farmers were asked to provide information on how often they generally sat down with their veterinarian to discuss certain issues or data (i.e., having a "table discussion"). This was done to account for the possibility that frequent table discussions influenced veterinarians' communication patterns and farmers' overall satisfaction and preparedness to adopt advice. Additionally, the number of cows that underwent pregnancy diagnosis during that particular HH\&PM farm visit was included, because all information given related to pregnancy diagnostics was coded as biomedical information and may have influenced the outcome variables satisfaction and preparedness to adhere. Finally, whether or not the HH\&PM farm visit included examination or treatment of a sick animal was included in the regression model because it may have affected farmers' satisfaction or preparedness to adopt recommendations; furthermore, veterinary communication is substantially different when veterinarians attend to a specific problem with an animal (Shaw et al., 2008; Ritter et al., 2018a).

\section{Satisfaction and Preparedness to Adopt Veterinary Recommendations}

After every HH\&PM farm visit, veterinarians handed a sealed and stamped envelope to the farmer containing a questionnaire that the farmer completed and returned directly to the researchers. The envelope included a note thanking the farmer for participation and assurance that the personal information provided in the questionnaire would not be shared with the veterinarian. In addition to information on farmer and farm demographics, the questionnaire elicited the farmer's satisfaction with the HH\&PM farm visit. This satisfaction survey, previously developed for a companion animal context (Coe et al., 2010), was slightly modified to be applicable to dairy farmers [e.g., by exchanging the word "pet(s)" for "animal(s)"; Figure A1 in Appendix]. Face validity of resulting questions was evaluated by obtaining informal feedback from a total of 9 large animal veterinarians, researchers, and dairy farmers. The satisfaction questionnaire consisted of 15 questions and farmers were asked to provide their responses on 6-point Likert scales [(1) poor, (2) fair, (3) good, (4) very good, (5) excellent, (6) could not be better or "unable to assess"]. An overall satisfaction score was obtained by averaging individual responses. In addition to studying farmers' satisfaction with various aspects of veterinary consultancy, the objective was to determine associations between visit-specific characteristics (e.g., communication patterns) and farmers' visit-specific satisfaction. Therefore, the 2 satisfaction ratings related to "cost" ("how well you understood the costs today" and "the veterinarian's discussion of cost with you") as well as the rating of "the veterinarian's recognition of the role your animals have in your life" were excluded from the overall satisfaction score. Compared with other items, farmers, in contrast to companion-animal consults, likely related these items less specifically to the particular HH\&PM farm visit.

In addition to assessment of their satisfaction, farmers were asked to rate their preparedness to adopt veterinary recommendations. For this, they provided their rating on a 6-point Likert scale [(1) absolutely, (3) somewhat, (6) not at all] for the question "After today's visit, are you prepared to take up the veterinarian's recommendation(s)?" Here, as for the satisfaction ratings, they had the option to select "unable to assess."

Demographic information pertaining to veterinarians was obtained by asking them to complete a questionnaire after they submitted all audio-video recordings. The questionnaire elicited information such as veterinarians' age, sex, years of experience in dairy practice, and extent of communication training.

\section{Statistical Analyses}

Stata IC15.0 (StataCorp LP, College Station, TX) was used for statistical analysis. Because of the relatively small sample size, a $P$-value $<0.10$ was considered significant. To assess intra-rater reliability for communication codes, Pearson correlation coefficients were calculated, whereas intra-rater reliability for global affect ratings was assessed by applying the identical 6-point Likert scale to calculate percentage of agreement for each category. Cronbach's $\alpha$ was calculated to evaluate internal consistency of the 12 satisfaction questions that were used for analysis (McArthur and Fitzgerald, 2013).

The association of potential predictor variables with overall satisfaction score (i.e., average of the 12 individual ratings) was assessed using linear regression. Farmers' preparedness to adopt recommendations was measured on a 6 -point Likert scale. However, 5 farmers (7\%) did not complete this question and all but 3 of the remaining farmers assigned a rating of "1" or "2." Therefore, this variable was dichotomized, with 1 cat- 
egory representing farmers that were "absolutely" (i.e., rating of 1) prepared to adopt veterinary recommendations and the other category representing a rating lower than "absolutely." Logistic regression was used to assess to association between this binary outcome variable and predictor variables.

Global affect ratings were dichotomized, based on the median, to avoid unstable regression estimates. Multicollinearity was reduced by excluding highly correlated (Pearson correlation coefficients $>0.80$ ) variables in multivariable models, or by centering affected variables through distraction of the mean.

Regression analysis was done in several steps. First, univariable associations of independent variables classified into 3 categories [general (demographic) factors, communication variables, and global affect ratings] with farmers' satisfaction and with farmers' preparedness to adopt veterinary recommendations were reported. Then, all variables within each of the 3 categories (independent of their association with outcome measures) were included in separate multivariable regression models. Building these 3 category-specific models per outcome measure was done as an intermediate step to select the most important variables for the final 2 models, comprising variables from all categories. Therefore, all variables that were $P<0.20$ in the Wald test or were identified to be confounders in the category-specific multivariable regression models were included in the respective final model ( 1 model to assess predictors for satisfaction and 1 model for farmers' preparedness to adopt advice).

Because there were at least $3 \mathrm{HH} \& \mathrm{PM}$ recordings per veterinarian, inclusion of veterinarian as a random effect in regression models was considered using a likelihood ratio test comparing the multilevel model with the model that did not account for clustering by veterinarian. If not significant, potential remaining clustering by veterinarian was accounted for by including clustered random errors. Then, backward-stepwise selection was used for selection of variables in multivariable models. Hence, variables with $P \geq 0.10$ in the Wald test were removed from the model and remaining coefficients were assessed for evidence of confounding through the removed variable. All possible and epidemiologically reasonable 2-way interactions between variables were investigated. Fit of the final model was evaluated using the Bayesian information criterion (BIC).

The relationship between farmers' satisfaction and farmers' preparedness to adopt veterinary recommendations was evaluated by including farmers' satisfaction score as a predicting variable in the logistic regression model, with preparedness to adopt advice as the outcome measure. Before model inclusion, we considered the possibility of satisfaction score being a mediating (i.e., intervening) variable between other independent variables and farmers' preparation to adopt advice (Judd and Kenny, 1981). If satisfaction were to be a full mediating variable, effects of other independent variables on satisfaction would also explain their effect on farmers' preparedness to adopt advice. Assessment of the relationship between variables was based on univariable associations (Judd and Kenny, 1981; Baron and Kenny, 1986) and principles of a causal diagram, in which potential causal associations are represented by arrows, based on qualitative and nonparametric assumptions (i.e., the assumption is that one variable causes another, without quantification of effect; Greenland et al., 1999; Shrier and Platt, 2008). However, whereas a causal diagram is generally used to identify variables that should be included in regression models and associations have to be acyclic, our purpose herein was to explore whether farmers' satisfaction should be considered a mediating variable (i.e., whether satisfaction lies on the pathway between independent variables and preparedness to adopt).

\section{RESULTS}

Intra-rater reliability was high, with an overall correlation on RIAS communication codes of 0.99 and global affect ratings having $100 \%$ agreement. The decision to exclude both cost-associated questions of satisfaction from regression analysis was supported by the relatively high proportion of farmers (17\%) who did not provide an answer to one or both cost-associated questions. Furthermore, based on preliminary review of recordings, only about half of the HH\&PM farm visits included any cost-associated discussion.

Mean age of participating veterinarians was $42 \mathrm{yr}$, whereas farmers averaged 39 yr (Table 2). Most participants were male $(90 \%$ of farmers and $71 \%$ of veterinarians). Farmers had, on average, 15 yr of experience as dairy producers, whereas veterinarians had $14 \mathrm{yr}$ of experience in dairy practice. On average, a veterinarian and farmer had worked together for $8 \mathrm{yr}$. Farms had on average 125 lactating cows, with $34.8 \mathrm{~kg}$ of milk production per cow per day, and a mean of $1.7 \mathrm{HH} \& \mathrm{PM}$ farm visits per month. Eight participating veterinarians stated having received extensive communication training ( $\geq 20 \mathrm{~h}$, including an official competence assessment), 5 veterinarians had never received any training, and 1 veterinarian had very limited training and was classified as "no training" for the analysis.

Overall, farmers appeared satisfied with veterinary services, giving average ratings $>4$ on the 6 -point Likert scale (Figure 1). Perception by the farmers of their involvement during the farm visit received the highest rating $($ mean $=5.3)$, whereas the 2 aspects related to 
Table 2. Demographic characteristics of study participants

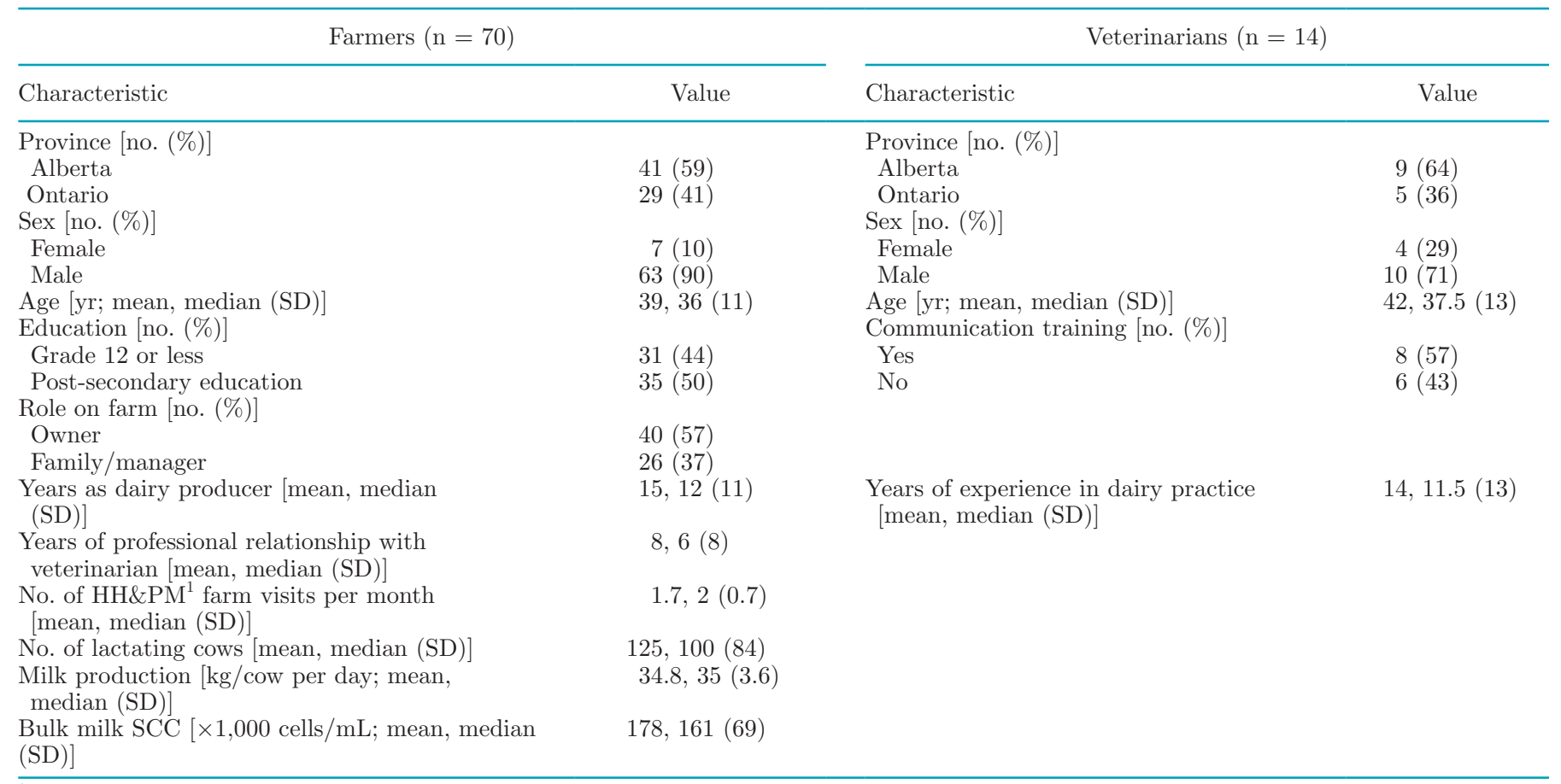

${ }^{1}$ Herd health and production management.

cost (i.e., veterinarian's discussion of cost and farmers' understanding of costs) received the lowest ratings (mean $=4.4$ and 4.6 , respectively). Farmers' overall average satisfaction scores, used to evaluate its association with various predictor variables, ranged from 2.8 to 6 . Mean overall satisfaction score was 5.1 , with a median and standard deviation of 5 and 0.7 , respectively. Internal consistency of the 12 questions eliciting farmers' satisfaction with the HH\&PM farm visit was very high (Cronbach's $\alpha=0.96$ ).

Thirty-eight $(58 \%)$ of the 65 farmers who answered this question indicated that they were "absolutely" prepared to adopt the veterinarian's advice after the HH\&PM farm visit, whereas 27 farmers $(42 \%)$ gave a lower rating, $24(37 \%)$ gave a rating of 2 , and 3 farmers (5\%) gave a rating of 3 .

\section{Regression Analyses}

To avoid model instability for multivariable regression models due to multicollinearity, veterinarian's age was centered and years as dairy veterinarian excluded because of the very high correlation with veterinarian's age (Pearson correlation coefficient $=0.97$ ). No female veterinarians $>38$ yr old participated, which led to misleading results in the regression model and the interaction term between sex of veterinarian and age. Therefore, the binary variable "male concordance" (i.e., both farmer and veterinarian being male versus one being female) was used.

Farmers' Satisfaction. Assessment of univariable associations between farmers' satisfaction score and general (demographic) variables (Table 3) revealed that satisfaction increased with increasing bulk milk SCC and was higher when the farmer was the owner. Furthermore, farmer satisfaction had a positive relationship with veterinarian's dominance and hurry, as perceived by the RIAS coder, whereas it had a negative association with number of years of the professional relationship between veterinarian and farmer and the number of cows that underwent pregnancy diagnosis during the HH\&PM farm visit.

Various variables were associated at $P<0.20$ in the category-internal multivariable regression models [i.e., separate models with variables representing general (demographic) factors, communication variables, and global effect ratings; Table 3, marked with an asterisk]. The final multivariable model included factors from all 3 categories to predict an overall satisfaction score (Table 4). In this final linear regression model $\left(\mathrm{R}^{2}=0.24\right.$, $\mathrm{BIC}=-115.68)$, farmers with post-secondary education were more satisfied with veterinary consultancy. Additionally, for recordings where either the farmer or veterinarian was female, satisfaction increased with increasing veterinarian age, whereas if both participants were male (i.e., male concordant interactions) satisfac- 


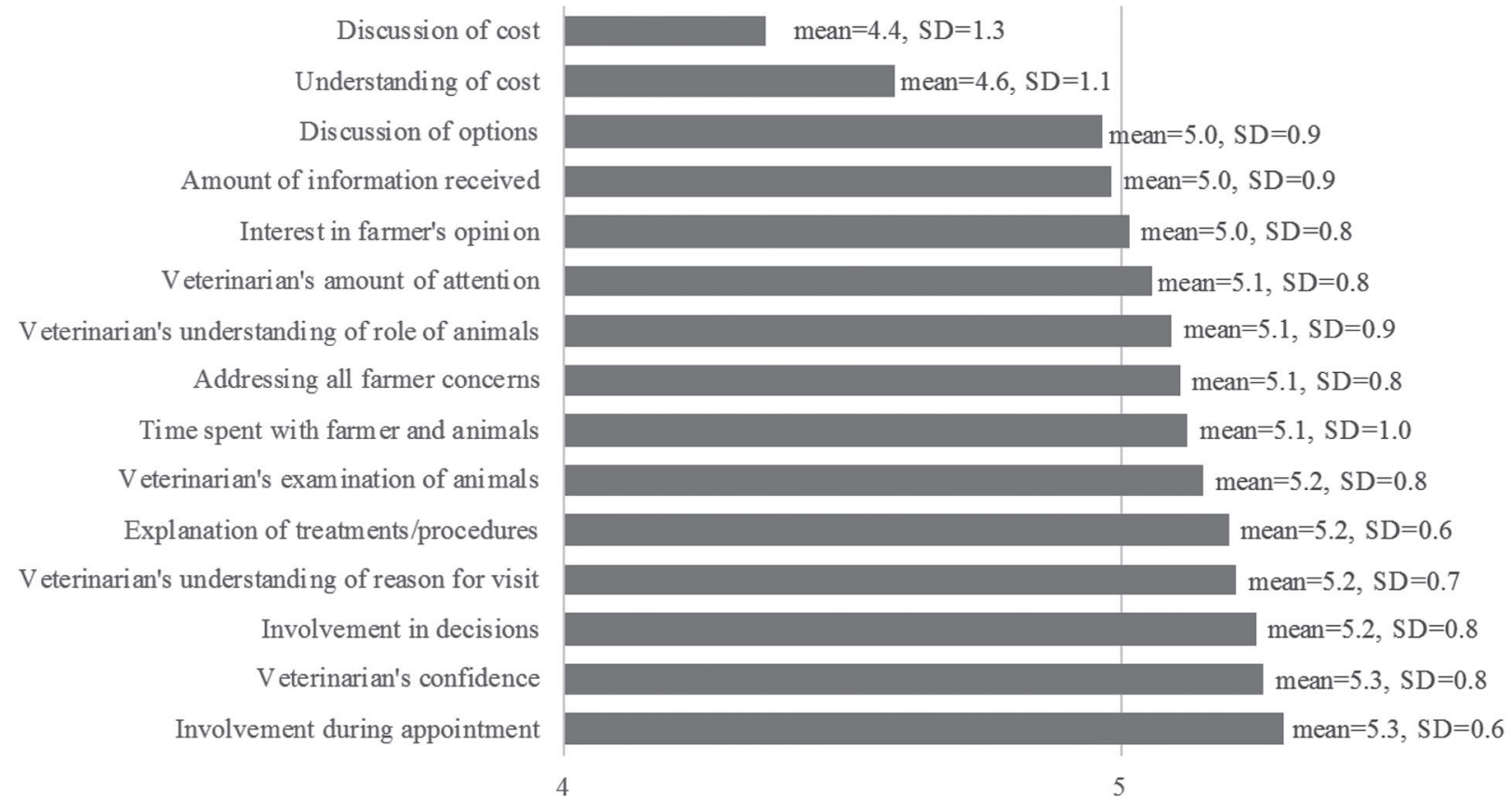

Figure 1. Farmers' satisfaction with various aspects of veterinary service during herd health and production management visits. The survey question was phrased as follows: "From today's visit, how would you rate ..." Farmers provided their answers on 6-point Likert scales, where 1 $=$ poor, $2=$ fair, $3=$ good, $4=$ very good, $5=$ excellent, and $6=$ could not be better.

tion was independent of veterinarian age. The ratio of total talk (i.e., total veterinary talk compared with total farmer talk) was negatively associated with farmer satisfaction; however, satisfaction of farmers increased with an increasing number of veterinary communication units being allocated to education and counseling (Table 4).

Preparedness to Adopt Veterinary Advice. When investigating the univariable relationship between all assessed factors and farmers' preparedness to adopt veterinary recommendations (Table 3), the ratio of total talk and number of farmer questions were negatively associated with farmers' preparedness to adopt recommendations. Furthermore, univariable logistic regression analysis indicated that satisfaction was a predictor of farmers' intention to adopt veterinary advice $($ coefficient $=1.28 ; 95 \% \mathrm{CI}=0.37-2.18 ; P=$ $0.006)$.

Satisfaction score was not deemed to be a full mediator between the relationship of independent variables and farmers' preparedness to adopt, based on the causal diagram and assessment of univariable associations. Therefore, satisfaction was included as a predicting variable in the multivariable logistic model, with preparedness to adopt advice as the outcome (Figure 2 ; Table 5). In the final multivariable logistic model (model fit: McFadden's pseudo- $\mathrm{R}^{2}=0.44$, BIC $=$ $-156.13)$, farmers' overall satisfaction score was posi- tively associated with their preparedness to adopt advice. Additionally, when the farmer had post-secondary education, the veterinarian used more farmer education and counseling and was more nervous (as perceived by the RIAS coder), and when farmers frequently had table discussions with their veterinarian, their preparedness to adopt veterinary advice increased. In contrast, veterinarian's age (for interactions with a female present) and number of communication units dedicated to veterinarian's information gathering (i.e., questions) were negatively associated with farmer preparedness to adopt advice. Furthermore, HH\&PM visits in Ontario compared with Alberta, number of farmer questions, and whether the RIAS coders perceived the veterinarian as more dominant had a negative relationship with farmers' preparedness to adopt recommendations.

\section{DISCUSSION}

In this study, various general (demographic) factors, specific communication tools, and veterinarians' global affective characteristics were associated with dairy farmers' satisfaction or farmers' self-perceived preparedness to adhere to veterinary advice after HH\&PM farm visits. Overall, farmers were satisfied with veterinary services, similar to farmers' satisfaction in the Netherlands (Jansen, 2010). However, compared with other questionnaire items, farmers were least satisfied with 
Table 3. Univariable associations $(P<0.20)$ of predictor variables with farmers' satisfaction and preparedness to adopt veterinary recommendations

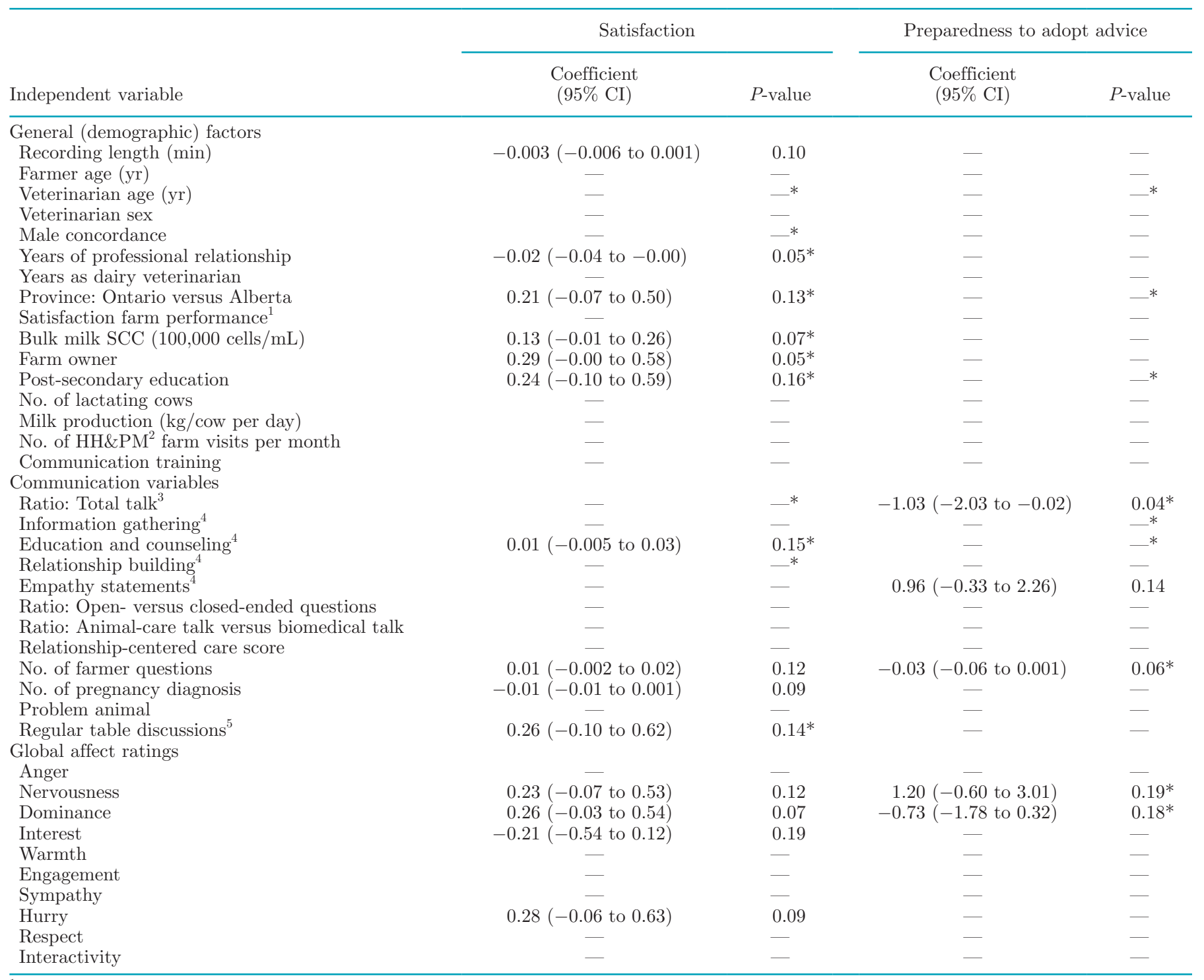

${ }^{1}$ Rated by the farmers on a 10-point Likert scale: (1) not at all satisfied to (10) extremely satisfied.

${ }^{2}$ Herd health and production management.

${ }^{3}$ Ratio of all veterinary talk divided by all farmer talk.

${ }^{4}$ As percentage of all veterinary talk.

${ }^{5}$ Defined as "often" or "always" versus less frequent (i.e., "sometimes," "rarely," "never").

*Variables with $P<0.20$ in subsequent multivariable category-specific regression models. An interaction term of veterinarian's age and male concordance was included in the multivariable models assessing demographic factors.

veterinarians' communication about costs associated with veterinary care and advice. Research to further explore this finding could improve our understanding of monetary implications associated with whole-herd management. Additionally, it was not within the scope of this study to assess why $42 \%$ of responding farmers did not state they were "absolutely" prepared to adopt veterinary advice. However, previous research reported that reasons could include lack of (perceived) ability, effectiveness, awareness, social pressure, or information (reviewed by Ritter at al., 2017).

Farmers who gave higher satisfaction ratings, were, self-reportedly, more prepared to adopt veterinary recommendations. Similarly, patient satisfaction has been linked to adherence to medical recommendations in a range of studies (e.g., Bartlett et al., 1984; Bultman and Svarstad, 2000; Linn et al., 2016). In a companionanimal context, pet owners who adhered to a surgery or 
Table 4. Multivariable associations $(P<0.10)$ between predictor variables and farmers' satisfaction

\begin{tabular}{lcc}
\hline & \multicolumn{1}{c}{ Satisfaction } \\
\cline { 2 - 3 } & $\begin{array}{c}\text { Coefficient } \\
(95 \% \text { CI })\end{array}$ & $P$-value \\
\hline Independent variable & $0.05(0.00$ to 0.09$)$ & 0.04 \\
\hline General (demographic) factors & $-0.35(-0.70$ to -0.01$)$ & 0.04 \\
$\quad$ Veterinarian age (yr) & $0.30(-0.03$ to 0.63$)$ & 0.07 \\
Male concordance & $-0.05(-0.09$ to -0.02$)$ & 0.01 \\
Post-secondary education & $-0.47(-0.96$ to 0.03$)$ & 0.06 \\
Interaction: Veterinarian age $\times$ male concordance $_{\text {Communication variables }}$ & $0.04(0.01$ to 0.07$)$ & 0.01 \\
$\quad$ Ratio: Total talk & & \\
Education and counseling $^{3}$ &
\end{tabular}

${ }^{1}$ Veterinarian and farmer were both male versus at least one of them was female.

${ }^{2}$ Ratio of all veterinary talk divided by all farmer talk.

${ }^{3}$ As percentage of all veterinary talk.

dentistry recommendation were considerably more satisfied with veterinary consultancy (Kanji et al., 2012). This study, therefore, supported previous findings; furthermore, we inferred that farmers' satisfaction might be a proxy for their preparedness to adopt veterinary recommendations.

Farmers' satisfaction increased with increasing age when either farmer or veterinarian was female, whereas it was the opposite for farmers' preparedness to adopt veterinary advice. Although Noro et al. (2018) did not report an interaction effect of age, stratification by sex dyads revealed that male patients were less satisfied with their male physicians compared with female patients with female physicians. If future research indicated substantial impacts of sex or age on the veterinarian-farmer relationship, this could have practical implications, such as the potential for pairing veterinarians with specific farmers given the opportunity (e.g., in larger clinics with several veterinarians). However, it should be emphasized that neither sex nor age directly

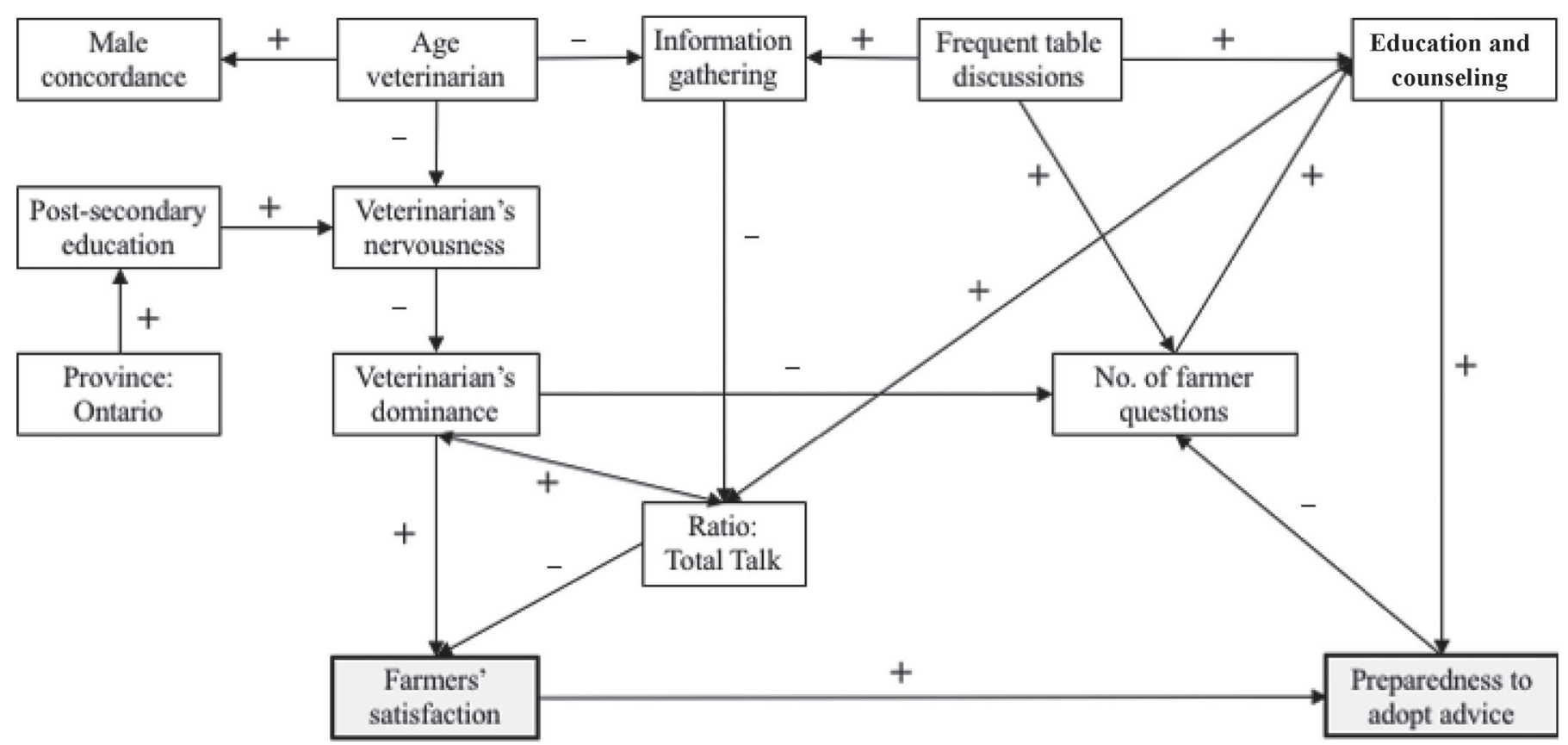

Figure 2. Causal diagram illustrating potential associations between farmers' satisfaction (exposure variable), farmers' preparedness to adopt veterinary advice (outcome variable), and covariates. Arrows represent assumed causal associations among variables $(+=$ positive; $-=$ negative) that were subsequently included in a multivariable regression model (see Table 5). Demographic variables, frequency of table discussions (i.e., how often veterinarian and farmer sit down to discuss herd health and production), farmers' satisfaction with the veterinary consultancy, and farmers' preparedness to adopt veterinary advice were assessed using questionnaires. Remaining variables were obtained through analysis of on-farm video recordings. Male concordance $=$ both veterinarian and farmer were male versus at least one of them was female. 
Table 5. Multivariable associations $(P<0.10)$ between predictor variables and farmers' preparedness to adopt veterinary advice

\begin{tabular}{|c|c|c|}
\hline \multirow[b]{2}{*}{ Independent variable } & \multicolumn{2}{|c|}{ Preparedness to adopt advice } \\
\hline & $\begin{array}{l}\text { Coefficient } \\
(95 \% \text { CI })\end{array}$ & $P$-value \\
\hline Farmers' overall satisfaction score & $3.25(1.83$ to 4.67$)$ & $<0.001$ \\
\hline \multicolumn{3}{|l|}{ General (demographic) factors } \\
\hline Veterinarian age (yr) & $-0.52(-0.84$ to -0.20 & $<0.01$ \\
\hline Male concordance & $2.89(0.24$ to 5.44$)$ & 0.03 \\
\hline Province: Ontario vs. Alberta & $-2.51(-3.96$ to -1.05$)$ & $<0.01$ \\
\hline Post-secondary education & $1.27(0.24$ to 2.29$)$ & 0.02 \\
\hline Interaction term: Veterinarian age $\times$ male concordance & $0.57(0.22$ to 0.91$)$ & $<0.01$ \\
\hline \multicolumn{3}{|l|}{ Communication variables } \\
\hline Information gathering $^{2}$ & $-0.20(-0.43$ to -0.03$)$ & 0.09 \\
\hline Education and counseling $^{2}$ & $0.11(0.01$ to 0.21$)$ & 0.03 \\
\hline No. of farmer questions & $-0.08(-0.14$ to -0.03$)$ & $<0.01$ \\
\hline Frequent table discussion ${ }^{3}$ & $2.28(0.53$ to 4.03$)$ & 0.01 \\
\hline \multicolumn{3}{|l|}{ Global affect ratings } \\
\hline Nervousness & $1.85(0.22$ to 3.48$)$ & 0.03 \\
\hline Dominance & $-3.08(-4.83$ to -1.34$)$ & $<0.01$ \\
\hline
\end{tabular}

influenced outcomes but rather that latent characteristics are represented by these demographics (e.g., older veterinarians may be more confident).

Farmers with higher bulk milk SCC were more satisfied; perhaps they were less critical in terms of farm management, similar to the finding that higher bulk milk SCC was associated with less precise practices and lower hygienic conditions (Barkema et al., 1999). This uncritical mindset may have extended to evaluation of their veterinarian. Farm owners were more satisfied than other farm workers (i.e., farm managers or family members), probably because they were in a position where they could choose whether or not to work with a particular veterinarian. However, years of professional relationship was negatively associated with satisfaction, indicating that either farmers' expectations increased or that veterinarians' efforts decreased as duration of the professional relationship increased. However, in multivariable analyses, none of these demographic factors remained significant and their importance for the veterinarian-farmer relationship was not conclusively established with this study. Nonetheless, consistently in both multivariable models, farmers with post-secondary education were more satisfied and more prepared to adopt veterinary advice. There are several possible explanations for these associations: These farmers may understand better why a veterinarian makes a particular recommendation, either because of their theoretical knowledge gained from formal education or through more comprehensive discussions with their veterinarian. Furthermore, they may feel more confident in their abilities to implement changes on their farm (i.e., high- er perceived behavioral control). However, veterinary practitioners should ensure that farmers, independent of education status, understand reasons behind their advice and feel confident implementing it.

Previous studies reported on positive associations of specific communication tools; for example, empathy statements, open-ended questions, and a high relationship-centered care score on outcomes such as satisfaction or adherence to advice (e.g., Roter and Hall, 1987; Kanji et al., 2012; McArthur and Fitzgerald, 2013); however, these findings could not be confirmed in the current study. Additionally, whether or not the veterinarian had received communication training was not associated with either outcome, perhaps because communication skills used by either group of veterinarians were very similar (Ritter et al., 2018a). However, more veterinarian talk than farmer talk tended to be negatively associated with farmers' satisfaction, although farmers generally appeared to appreciate education and counseling by veterinarians. Similarly, Smith et al. (1981) concluded that patients who received more information from their physician were more satisfied with the interaction, whereas Hall and Wapenaar (2012) reported that $81 \%$ of dairy farmers in the UK valued discussions with their veterinarian about topics such as herd health and welfare issues; unfortunately, only $26 \%$ of veterinarians initiated discussions. Pet owners interviewed for a qualitative Canadian study indicated a lack of satisfaction with veterinary care because of inadequate information about procedures, costs, or possible outcomes (Coe et al., 2008). In this study, farmers who asked more questions during the HH\&PM 
farm visit were less prepared to adopt veterinary recommendations. We concluded that veterinarians need to balance between providing information and giving farmers the opportunity to express their viewpoints. Sufficient education and counseling were an essential aspect of HH\&PM farm visits, and veterinarians should be sensitive to farmers' questions because lack thereof may indicate insufficient preparedness to adopt advice.

Farmers were less prepared to adopt recommendations if visited by veterinarians who were perceived as more dominant. Therefore, we concluded that a paternalistic approach (i.e., clinicians being the main authority and making decisions without taking the client's or patient's perspectives into account) was less desirable, a conclusion reached in various studies (e.g., Guadagnoli and Ward, 1998; Coe et al., 2008; Bard et al., 2017). Hence, veterinarians should always attempt to involve farmers in decision-making processes, ensuring that these decisions are aligned with the farmers' goals and aspirations. Farmers who were visited by veterinarians with higher levels of nervousness were also more prepared to adopt their advice, which seemed counterintuitive, because we would expect that veterinarian's confidence would positively influence farmers' trust in their advice. However, in contrast to other global affect ratings that had a more balanced distribution, only 11 recordings from 7 veterinarians were rated as having a level of veterinary nervousness $>1$ on the 6 -point Likert scale. Because of these statistical limitations, this finding should be interpreted with caution.

Farmers who stated that they had frequent table discussions with their veterinarian felt more prepared to adopt veterinary advice, which has important implications for veterinary practitioners. As such, veterinarians should make an effort to include table discussions as a regular aspect of HH\&PM farm visits. We hypothesized that this would be especially beneficial if this opportunity was used to specifically address farmers' concerns and provide detailed answers.

Assessment of farmers' satisfaction and self-perceived preparedness to adopt veterinary advice are arguably suboptimal outcome measures because the ultimate goal is to link specific (communication) factors to the odds of definite on-farm improvements such as the actual implementation of recommended changes, reduction of disease prevalence and incidence, or increases in milk production, economic profit, or animal welfare. However, because of the difficulty and large scope of conducting such a longitudinal study, which would likely require restriction to a particular topic of interest, this research focused on using farmers' attitudes as outcome measures. Considering that peoples' attitudes are generally believed to be predictors of their actions (Ajzen, 1991), assessment of dairy farmers' attitudes was deemed appropriate as a more immediately available outcome measure. However, future research assessing outcomes such as aforementioned ones (e.g., implementation of advice) is advisable, to provide a more comprehensive description of potential and limitations of veterinary communication.

Study participants' demographics were comparable to those reported in other studies, in terms of age, sex, farm milk production, number of lactating cows per farm, and duration of veterinary dairy experience (Luby et al., 2013; Jelinski and Barth, 2015; Ritter et al., 2015; Winder et al., 2016; Canadian Dairy Information Centre, 2017), supporting the external validity of the study. However, there were limitations to this study, some of which have been discussed (Ritter et al., 2018a). Specifically, being video-audio recorded could have altered the communication tools used and the veterinary affective characteristics as perceived by the RIAS coders. Regardless, we believe that there was no superior feasible alternative to collect such comprehensive data regarding on-farm interactions.

Questions used to assess dairy farmers' satisfaction were derived from a survey instrument developed for a companion animal context, where survey reliability and validity were assessed (Coe et al., 2010). A similar test of the instrument for the dairy farm context, going beyond calculation of Cronbach's $\alpha$ for internal consistency and informal assessment of face validity, would have been beneficial. The questionnaire assessed farmers' perceptions of whether they felt prepared to adopt veterinary advice after HH\&PM visits. Preliminary review of the recordings and the high response rate $(93 \%)$ to this question suggested that interactions generally included one or more veterinary recommendations; however, farmers' replies to this question may need to be regarded as generic and not necessarily HH\&PM visit-specific.

Roter interaction analysis system global affect ratings are frequently used in medical communication research, and correlations with other tools for evaluating medical interactions support its validity [e.g., physician-caregiver relationship scales (Cox et al., 2008) and Georgetown PAtient-CEnteredness Rating Scale (Talisman et al., 2018)]. However, it must be acknowledged that this measure is subjective.

Variations in selection processes for veterinarians could have contributed to divergent results between provinces for farmers' preparedness to adopt advice. Ontario veterinarians had registered for an educational course and volunteered to participate in response to an email invitation. These veterinarians may use different communication patterns as part of their on-farm consultancy compared with their colleagues in Alberta. They could have volunteered either because they were 
especially confident in their consultancy skills or because they regarded this study as an opportunity to receive feedback and improve their skills. That Ontario farmers were less likely to feel prepared to adopt advice supported the latter scenario. Overall, it is possible that veterinarians' communication skills, farmers' satisfaction, and farmers' preparedness to adopt advice were overestimated because of nonrandom sampling strategies. In particular, it was not possible to assess whether veterinarians selected farms representative in terms of herd size and farm management and did not only select farmers with whom they had a good relationship. However, to the best of our knowledge, this is the first study to assess effects of dairy practitioners' communication on outcome measures. As such, it has added to the knowledge base and highlighted the importance of effective veterinary communication.

\section{CONCLUSIONS}

In addition to demographic factors such as veterinarian's age and male concordance during farm visits, several communication tools and veterinarians' affective attributes were associated with farmers' satisfaction and preparedness to adopt veterinary advice. Veterinary consultancy could benefit from increased use of certain communication aspects, such as farmer education, counseling, and table discussions, whereas veterinarians' dominance, including a relatively large amount of veterinary talk, appeared to have negative effects on farmers' perceptions. Results of this study can inform veterinary practitioners and veterinary educators aiming to improve veterinary communication and consultancy skills.

\section{ACKNOWLEDGMENTS}

This study was funded by the Margaret Gunn Endowment for Animal Research (University of Calgary, AB, Canada), the Izaak Walton Killam Trust (University of Calgary, AB, Canada), and Canada's Natural Sciences and Engineering Research Council (NSERC; Ottawa, ON, Canada) Industrial Research Chair Program, with industry contributions from Alberta Milk (Edmonton, AB, Canada), Dairy Farmers of Canada (Ottawa, ON, Canada), Dairy Farmers of Manitoba (Winnipeg, MB, Canada), British Columbia Dairy Association (Burnaby, BC, Canada), Westgen Endowment Fund (Milner, BC, Canada), Canadian Dairy Network (Guelph, ON, Canada), and CanWest DHI (Guelph, ON, Canada). The authors thank John Kastelic (Department of Production Animal Health, University of Calgary, Calgary, $\mathrm{AB}$, Canada) for editing the manuscript.

\section{REFERENCES}

Adams, C. L., and S. Kurtz. 2017. Skills for Communicating in Veterinary Medicine. 1st ed. MHRI Publishing, Parsippany, NJ.

Ajzen, I. 1991. The theory of planned behavior. Organ. Behav. Hum. Decis. Process. 50:179-211.

Bard, A. M., D. C. Main, A. M. Haase, H. R. Whay, E. J. Roe, and K. K. Reyher. 2017. The future of veterinary communication: Partnership or persuasion? A qualitative investigation of veterinary communication in the pursuit of client behaviour change. PLoS One 12:e171380

Barkema, H. W., Y. H. Schukken, T. J. G. M. Lam, M. L. Beiboer, G. Benedictus, and A. Brand. 1999. Management practices associated with the incidence rate of clinical mastitis. J. Dairy Sci. $82: 1643-1654$.

Baron, R. M., and D. A. Kenny. 1986. The moderator-mediator variable distinction in social psychological research: Conceptual, strategic, and statistical considerations. J. Pers. Soc. Psychol. 51:1173-1182.

Bartlett, E. E., M. Grayson, R. Barker, D. M. Levine, A. Golden, and S. Libber. 1984. The effects of physician communications skills on patient satisfaction; recall, and adherence. J. Chronic Dis. $37: 755-764$.

Bultman, D. C., and B. L. Svarstad. 2000. Effects of physician communication style on client medication beliefs and adherence with antidepressant treatment. Patient Educ. Couns. 40:173-185.

Canadian Dairy Information Centre. 2017. Dairy facts and figures. Accessed Sep. 29, 2018. www.dairyinfo.gc.ca.

Coe, J. B., C. L. Adams, and B. N. Bonnett. 2008. A focus group study of veterinarians' and pet owners' perceptions of veterinarian-client communication in companion animal practice. J. Am. Vet. Med. Assoc. 233:1072-1080.

Coe, J. B., C. L. Adams, K. Eva, S. Desmarais, and B. N. Bonnett. 2010. Development and validation of an instrument for measuring appointment-specific client satisfaction in companion-animal practice. Prev. Vet. Med. 93:201-210.

Cox, E. D., M. A. Smith, R. L. Brown, and M. A. Fitzpatrick. 2008 Assessment of the physician-caregiver relationship scales (PCRS). Patient Educ. Couns. 70:69-78.

Derks, M., B. van Woudenbergh, M. Boender, W. Kremer, T. van Werven, and H. Hogeveen. 2013. Veterinarian awareness of farmer goals and attitudes to herd health management in The Netherlands. Vet. J. 198:224-228.

Greenland, S., J. Pearl, and J. M. Robins. 1999. Causal diagrams for epidemiologic research. Epidemiology 10:37-48.

Guadagnoli, E., and P. Ward. 1998. Patient participation in decision making. Soc. Sci. Med. 47:329-339.

Hall, J., and W. Wapenaar. 2012. Opinions and practices of veterinarians and dairy farmers towards herd health management in the UK. Vet. Rec. 170:441

Jansen, J. 2010. Mastitis and farmer mindset. Towards effective communication strategies to improve udder health management on Dutch dairy farms. PhD Thesis. Wageningen University, Wageningen, the Netherlands.

Jansen, J., H. Klinkert, R. J. Renes, and T. J. G. M. Lam. 2010. Effective communication of veterinary advice: interaction between the veterinarian and the farmer. Pages 185-191 in Mastitis Research into Practice, Proc. 5th IDF Mastitis Conf., Christchurch, New Zealand. J. E. Hillerton, ed. Vetlearn, Wellington, New Zealand.

Jelinski, M. D., and K. K. Barth. 2015. Survey of western Canadian veterinary practices: A demographic profile. Can. Vet. J. 56:12451251.

Judd, C. M., and D. A. Kenny. 1981. Process analysis: Estimating mediation in treatment evaluations. Eval. Rev. 5:602-619.

Kanji, N., J. B. Coe, C. L. Adams, and J. R. Shaw. 2012. Effect of veterinarian-client-patient interactions on client adherence to dentistry and surgery recommendations in companion-animal practice. J. Am. Vet. Med. Assoc. 240:427-436.

King, A., and R. B. Hoppe. 2013. "Best practice" for patient-centered communication: A narrative review. J. Grad. Med. Educ. 5:385393. 
Linn, A. J., J. C. M. van Weert, L. van Dijk, R. Horne, and E. G. Smit. 2016. The value of nurses' tailored communication when discussing medicines: Exploring the relationship between satisfaction, beliefs and adherence. J. Health Psychol. 21:798-807.

Luby, C. D., K. McIntyre, and M. D. Jelinski. 2013. Skills required of dairy veterinarians in western Canada: A survey of practicing veterinarians. Can. Vet. J. 54:267-270.

McArthur, M. L., and J. R. Fitzgerald. 2013. Companion animal veterinarians' use of clinical communication skills. Aust. Vet. J. 91:374-380.

Noro, I., D. L. Roter, S. Kurosawa, Y. Miura, and M. Ishizaki. 2018. The impact of gender on medical visit communication and patient satisfaction within the Japanese primary care context. Patient Educ. Couns. 101:227-232.

Petrovski, K. R., and M. McArthur. 2015. The art and science of consultations in bovine medicine: Use of Modified Calgary-Cambridge Guides. Maced. Vet. Rev. 38:137-147.

Ritter, C., C. L. Adams, D. F. Kelton, and H. W. Barkema. 2018a Clinical communication patterns of veterinary practitioners during dairy herd health and production management farm visits. J. Dairy Sci. 101:10337-10350.

Ritter, C., H. W. Barkema, and C. L. Adams. 2018b. Action cameras and the Roter Interaction Analysis System to assess clinical interactions of veterinary practitioners and their clients. Vet. Rec. 182:227.

Ritter, C., J. Jansen, S. Roche, D. F. Kelton, C. L. Adams, K. Orsel, R. J. Erskine, G. Benedictus, T. Lam, and H. W. Barkema. 2017. Invited review: Determinants of farmers' adoption of managementbased strategies for infectious disease prevention and control. J. Dairy Sci. 100:3329-3347.

Ritter, C., G. P. Kwong, R. Wolf, C. Pickel, M. Slomp, J. Flaig, S. Mason, C. L. Adams, D. F. Kelton, J. Jansen, J. De Buck, and H. W. Barkema. 2015. Factors associated with participation of Alberta dairy farmers in a voluntary, management-based Johne's disease control program. J. Dairy Sci. 98:7831-7845.

Robinson, J. D., and J. Heritage. 2006. Physicians' opening questions and patients' satisfaction. Patient Educ. Couns. 60:279-285.

Roter, D., and S. Larson. 2002. The Roter Interaction Analysis System (RIAS): Utility and flexibility for analysis of medical interactions. Patient Educ. Couns. 46:243-251.
Roter, D. L., and J. A. Hall. 1987. Physicians interviewing styles and medical information obtained from patients. J. Gen. Intern. Med. $2: 325-329$

Sari, M. I., Y. S. Prabandari, and M. Claramita. 2016. Physicians' professionalism at primary care facilities from patients' perspective: The importance of doctors' communication skills. J. Family Med. Prim. Care 5:56

Shaw, J. R., C. L. Adams, B. N. Bonnett, S. Larson, and D. L. Roter. 2004. Use of the Roter interaction analysis system to analyze veterinarian-client-patient communication in companion animal practice. J. Am. Vet. Med. Assoc. 225:222-229.

Shaw, J. R., C. L. Adams, B. N. Bonnett, S. Larson, and D. L. Roter. 2008. Veterinarian-client-patient communication during wellness appointments versus appointments related to a health problem in companion animal practice. J. Am. Vet. Med. Assoc. 233:15761586.

Shaw, J. R., B. N. Bonnett, C. L. Adams, and D. L. Roter. 2006. Veterinarian-client-patient communication patterns used during clinical appointments in companion animal practice. J. Am. Vet. Med. Assoc. 228:714-721.

Shrier, I., and R. W. Platt. 2008. Reducing bias through directed acyclic graphs. BMC Med. Res. Methodol. 8:70.

Silverman, J., S. Kurtz, and J. Draper. 2013. Skills for Communicating with Patients. 3rd ed. Radcliffe Publishing, London, UK.

Smith, C. K., E. Polis, and R. R. Hadac. 1981. Characteristics of the initial medical interview associated with patient satisfaction and understanding. J. Fam. Pract. 12:283-288.

Sorge, U., D. Kelton, K. Lissemore, A. Godkin, S. Hendrick, and S. Wells. 2010. Attitudes of Canadian dairy farmers toward a voluntary Johne's disease control program. J. Dairy Sci. 93:1491-1499.

Talisman, N. W., A. Hurtado-de-Mendoza, P. A. Saunders, and B L. Green. 2018. Validation of a standardized patient checklist for patient-centered communication: The G-PACER. Med. Sci. Educ. $28: 367-373$.

Williams, D., and J. Jewell. 2012. Family-centred veterinary medicine: learning from human paediatric care. Vet. Rec. 170:79-80.

Winder, C. B., S. J. LeBlanc, D. B. Haley, K. D. Lissemore, M. A. Godkin, and T. F. Duffield. 2016. Practices for the disbudding and dehorning of dairy calves by veterinarians and dairy producers in Ontario, Canada. J. Dairy Sci. 99:10161-10173. 


\section{Appendix}

\begin{tabular}{|c|c|c|c|c|c|c|c|}
\hline & $\begin{array}{l}\text { Could } \\
\text { not be } \\
\text { better }\end{array}$ & Excellent & $\begin{array}{l}\text { Very } \\
\text { good }\end{array}$ & Good & Fair & Poor & $\begin{array}{l}\text { Unable } \\
\text { to assess }\end{array}$ \\
\hline $\begin{array}{l}\text { The amount of attention the } \\
\text { veterinarian gave your animals }\end{array}$ & $\square$ & $\square$ & $\square$ & $\square$ & $\square$ & $\square$ & $\square$ \\
\hline $\begin{array}{l}\text { How well the veterinarian understood } \\
\text { the reason for the visit }\end{array}$ & $\square$ & $\square$ & $\square$ & $\square$ & $\square$ & $\square$ & $\square$ \\
\hline $\begin{array}{l}\text { Your sense of the vet's confidence } \\
\text { interacting with you and your animals }\end{array}$ & $\square$ & 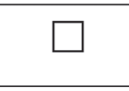 & $\square$ & & $\square$ & $\square$ & $\square$ \\
\hline $\begin{array}{l}\text { How well the veterinarian involved } \\
\text { you in the entire appointment }\end{array}$ & $\square$ & $\square$ & $\square$ & $\square$ & $\square$ & $\square$ & $\square$ \\
\hline $\begin{array}{l}\text { The veterinarian's examination of your } \\
\text { animals }\end{array}$ & $\square$ & $\square$ & $\square$ & $\square$ & $\square$ & $\square$ & $\square$ \\
\hline $\begin{array}{l}\text { How well the veterinarian explained } \\
\text { treatments and procedures }\end{array}$ & $\square$ & $\square$ & $\square$ & $\square$ & $\square$ & $\square$ & ] \\
\hline $\begin{array}{l}\text { How well the veterinarian involved } \\
\text { you in decisions }\end{array}$ & $\square$ & & & & $\square$ & $\square$ & 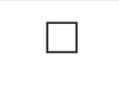 \\
\hline $\begin{array}{l}\text { How well you understood the costs } \\
\text { today }\end{array}$ & $\square$ & $\square$ & $\square$ & $\square$ & $\square$ & $\square$ & $\square$ \\
\hline $\begin{array}{l}\text { The veterinarian's discussion of } \\
\text { options with you }\end{array}$ & $\square$ & $\square$ & $\square$ & $\square$ & $\square$ & $\square$ & $\square$ \\
\hline $\begin{array}{l}\text { The veterinarian's discussion of the } \\
\text { cost with you }\end{array}$ & $\square$ & $\square$ & $\square$ & $\square$ & $\square$ & $\square$ & $\square$ \\
\hline $\begin{array}{l}\text { The interest the veterinarian expressed } \\
\text { in your opinion }\end{array}$ & $\square$ & $\square$ & $\square$ & $\square$ & $\square$ & $\square$ & $\square$ \\
\hline $\begin{array}{l}\text { The amount of information you } \\
\text { received from the veterinarian }\end{array}$ & $\square$ & $\square$ & $\square$ & $\square$ & $\square$ & $\square$ & $\square$ \\
\hline $\begin{array}{l}\text { How well the veterinarian addressed } \\
\text { all of your concerns }\end{array}$ & $\square$ & $\square$ & $\square$ & $\square$ & $\square$ & $\square$ & $\square$ \\
\hline $\begin{array}{l}\text { The veterinarian's recognition of the } \\
\text { role your animals have in your life }\end{array}$ & $\square$ & $\square$ & $\square$ & $\square$ & $\square$ & $\square$ & $\square$ \\
\hline $\begin{array}{l}\text { The amount of time the veterinarian } \\
\text { spent with you and your animals }\end{array}$ & $\square$ & $\square$ & $\square$ & $\square$ & $\square$ & $\square$ & $\square$ \\
\hline
\end{tabular}

Figure A1. Survey questions eliciting farmers' satisfaction with the veterinary herd health and production management visit (modified from Coe et al., 2010, by making minor changes; reprinted with permission from Elsevier). 